\title{
OPEN BTN2A2 protein negatively regulates $T$ cells to ameliorate collagen-induced arthritis in mice
}

\begin{abstract}
Xueping $\mathrm{He}^{1,8}$, Rong Hu${ }^{1,2,8}$, Peng Luo ${ }^{3,4}$, Jie Gao ${ }^{1}$, Wenjiang Yang ${ }^{1}$, Jiaju $\mathrm{Li}^{1}$, Youjiao Huang ${ }^{1}$, Feng Han $^{5}$, Laijun Lai ${ }^{6 \bowtie} \&$ Min Su ${ }^{1,7 凶}$

Rheumatoid arthritis (RA) is an autoimmune disorder characterized by persistent inflammatory responses in target tissues and organs, resulting in the destruction of joints. Collagen type II (CII)induced arthritis (CIA) is the most used animal model for human RA. Although BTN2A2 protein has been previously shown to inhibit $T$ cell functions in vitro, its effect on autoimmune arthritis has not been reported. In this study, we investigate the ability of a recombinant BTN2A2-IgG2a Fc (BTN2A2-Ig) fusion protein to treat CIA. We show here that administration of BTN2A2-Ig attenuates established $\mathrm{CIA}$, as compared with control Ig protein treatment. This is associated with reduced activation, proliferation and Th1/Th17 cytokine production of T cells in BTN2A2-Ig-treated CIA mice. BTN2A2-Ig also inhibits CII-specific T cell proliferation and Th1/Th17 cytokine production. Although the percentage of effector T cells is decreased in BTN2A2-Ig-treated CIA mice, the proportions of naive $T$ cells and regulatory T cells is increased. Furthermore, BTN2A2-Ig reduces the percentage of proinflammatory M1 macrophages but increases the percentage of anti-inflammatory M2 macrophages in the CIA mice. Our results suggest that BTN2A2-Ig protein has the potential to be used in the treatment of collagen-induced arthritis models.
\end{abstract}

Autoimmune diseases including rheumatoid arthritis (RA) are characterized by chronic and persistent inflammation in target tissues and organs. During RA progression, the synovial lining layer of the inflamed joints increases its thickness as a result of synovial hyperplasia and inflammation ${ }^{1}$. Collagen-induced arthritis (CIA) is a wellcharacterized mouse model for human RA, in which injection of type II collagen (CII) into male DBA/1 mice induces swelling and progressive inflammation in joints, leading to arthritis. The CIA model has been used extensively to identify potential pathogenic mechanisms, and to design and test new therapeutics for human $\mathrm{RA}^{2,3}$.

Studies have shown that $\mathrm{T}$ cells play a pivotal role in the pathogenesis of $\mathrm{RA}^{4-7}$. $\mathrm{T}$ cells are regulated by costimulatory and coinhibitory molecules. T cell coinhibitory molecules are critical for maintaining peripheral tolerance to avoid autoimmune disease. Among the $\mathrm{T}$ cell regulators, the B7 family members are of central importance. The importance of the B7 family is illustrated by the FDA's approval of several drugs for the treatment of immune-related diseases including RA by targeting the ligands or receptors of the B7 family members, such as CTLA-4.

Butyrophilins constitute a family of transmembrane proteins consisting of butyrophilin (BTN), BTN-like (BTNL), and selection and upkeep of intraepithelial T cell (SKI NT) proteins ${ }^{8-14}$. The extracellular BTN domains share sequence and structural similarity with the B7 family members. The functions of some BTN and BTNL members also like the B7 family members, either inhibiting or stimulating T cell activation and proliferation ${ }^{15-25}$. Therefore, BTN and BTNL molecules have been proposed to belong to an extended B7 family $\mathrm{y}^{23,26,27}$.

\footnotetext{
${ }^{1}$ Department of Human Histology and Embryology, School of Basic Medical Sciences, Center for Tissue Engineering and Stem Cell Research, Guizhou Medical University (North Campus), Guiyang 550025, Guizhou, China. ${ }^{2}$ Translational Medicine Research Center, Guizhou Medical University, Guiyang 550025, Guizhou, China. ${ }^{3}$ School of Public Health, The Key Laboratory of Environmental Pollution Monitoring and Disease Control, Ministry of Education/ Guizhou Provincial Engineering Research Center of Food Nutrition and Health Guizhou Medical University, Guiyang 550025, Guizhou, China. ${ }^{4}$ State Key Laboratory of Functions and Applications of Medicinal Plants, Guizhou Medical University, Guiyang 550014, China. ${ }^{5}$ Department of Neurosurgery, The Affiliated Hospital of Guizhou Medical University, Guiyang 550004, Guizhou, China. ${ }^{6}$ Department of Allied Health Science, University of Connecticut, 1390 Storrs Road, Storrs, CT 06269, USA. ${ }^{7}$ Key Laboratory for Adult Stem Cell Translational Research, Chinese Academy of Medical Sciences, Guiyang 550004, Guizhou, China. ${ }^{8}$ These authors contributed equally: Rong Hu and Xueping He. ${ }^{\varpi}$ email: laijun.lai@uconn.edu; sumin@gmc.edu.cn
} 
It has been reported that BTN2A2 is expressed on B cells, DCs, and macrophages and the expression levels are upregulated upon activation ${ }^{19,21}$. BTN2A2 is also expressed on thymic epithelial cells (TECs) ${ }^{21}$. The BTN2A2 putative receptor is expressed on activated $\mathrm{T}$ cells ${ }^{21}$. BTN2A2 protein inhibits $\mathrm{T}$ cell proliferation, metabolism and Th1 cytokine production ${ }^{21}$. BTN2A2 inhibits TCR signaling molecules including CD3s, Zap70, and subsequent Erk1/2 activation ${ }^{19}$. BTN2A2 also reduces PI3K and Akt signaling ${ }^{19}$. BTN2A2 induces the production of $\mathrm{CD} 4^{+} \mathrm{CD} 25^{+} \mathrm{Foxp}^{+}$regulatory T cells (Tregs) ${ }^{19}$. Btn2a2-deficient mice have enhanced effector $\mathrm{CD} 4^{+}$and $\mathrm{CD} 8^{+} \mathrm{T}$ cell responses, impaired $\mathrm{CD} 4^{+}$regulatory $\mathrm{T}$ cell induction, and exacerbated experimental autoimmune encephalomyelitis ${ }^{8}$.

However, the ability of BTN2A2 protein to affect immune responses in vi-vo has not been reported. It has been reported that $B \operatorname{tn} 2 a 2$ is a RA-associated gene ${ }^{28}$. In this study, we produced a recombinant mouse BTN2A2-IgG2a Fc (mBTN2A2-Ig) fusion protein and set out to investigate the ability of the protein to affect CIA.

\section{Results}

BTN2A2 protein is expressed on T cells and APCs. We first analyzed the expression of BTN2A2 protein on the cell surface of mouse immune cells by flow cytometry using a commercially available anti-mouse BTN2A2 antibody. BTN2A2 protein was expressed weakly on the cell surface of resting $\mathrm{CD}_{4}^{+}$or $^{\mathrm{CD}} 8^{+} \mathrm{T}$ cells and the expression levels were slightly increased upon activation by anti-CD3 antibody although the differences did not reach significant levels (Fig. 1A,B). BTN2A2 protein was also expressed weakly on resting CD11 ${ }^{+}$ dendritic cells (DCs), F4/80 ${ }^{+}$macrophages, and $\mathrm{CD} 19^{+} \mathrm{B}$ cells, and the expression levels on these cells were significantly upregulated upon activation by LPS. (Fig. 1A,B). These results suggest that endogenous BTN2A2 is an integral cell surface protein that is expressed on resting and activated T cells, DCs, macrophages and B cells.

The putative BTN2A2 receptor is expressed on activated T cells. To determine the expression pattern of the putative mBTN2A2 receptor, we constructed a mouse BTN2A2-Ig fusion protein that contains the extracellular domain of BTN2A2 and the constant region of mouse IgG2a (Supplementary Fig. 1). Purified BTN2A2-Ig fusion protein and control mouse IgG2a Fc (control Ig) were biotinylated. Splenocytes from C57BL/6 mice were stained with the biotinylated proteins, followed by Streptavidin-PE. The binding of BTN2A2-Ig or control Ig to immune cells was analyzed by flow cytometry. We found that BTN2A2-Ig weakly bound to resting $\mathrm{CD} 4^{+}$and $\mathrm{CD} 8^{+} \mathrm{T}$ cells but the binding to anti-CD3 antibody activated $\mathrm{CD} 4^{+}$and $\mathrm{CD} 8^{+} \mathrm{T}$ cells was significantly increased (Fig. 2A,B). The results suggest that T cells, especially activated CD4 and CD8 T cells, express the putative BTN2A2 receptor.

We also analyzed the expression of the putative BTN2A2 receptor on other immune cells. We found that BTN2A2-Ig did not bind to resting CD11 $\mathrm{c}^{+} \mathrm{DCs}, \mathrm{F} 4 / 80^{+}$macrophages, and CD19+ $\mathrm{B}$ cells but bound weekly to these cells upon activation by LPS (Fig. 2A,B). The data suggest that activated DCs, macrophages and B cells express low levels of the putative BTN2A2 receptor. Our data are in agreement with previous reports ${ }^{19,21}$.

BTN2A2-Ig fusion protein has inhibitory effect on T cells in vitro. To determine whether BTN2A2Ig protein have an affect on $\mathrm{T}$ cell activation. The spleen of $\mathrm{C} 57 \mathrm{BL} / \mathrm{c}$ mice was taken and $\mathrm{T}$ cells were stimulated by anti-CD3 antibody and cultured with graded dose of BTN2A2-Ig (1600 ng, $3200 \mathrm{ng}$ and $6400 \mathrm{ng} / \mathrm{ml})$ or control Ig of equal molar mass for 3 days. Since CD69 is an early marker of T cell activation, the expression of CD69 in $\mathrm{CD}^{+} \mathrm{T}$ cells and $\mathrm{CD}^{+} \mathrm{T}$ cells was analyzed after $16-18 \mathrm{~h}$ of culture. As shown in Fig. $3 \mathrm{~A}$, the expression of $\mathrm{CD} 69$ on $\mathrm{CD}^{+} \mathrm{T}$ cells and $\mathrm{CD} 8^{+} \mathrm{T}$ cells significantly decreased in a dose-dependent manner after BTN2A2-Ig treatment. The results showed that BTN2A2 could inhibit the activation of $\mathrm{CD} 4^{+} \mathrm{T}$ cells and $\mathrm{CD} 8^{+} \mathrm{T}$ cells.

In order to further verify the effect of BTN2A2-Ig protein on T cell activation, we analyzed the effect of BTN2A2-Ig on the expression levels of CD44 and CD62L. As shown in Fig. 3B, BTN2A2-Ig treatment increased the percentage of CD $44^{\text {lo }} \mathrm{CD} 62 \mathrm{~L}^{\text {hi }}$ naive CD4 and CD8 T cells, but decreased the percentage of CD44 ${ }^{\text {hi }} \mathrm{CD} 62 \mathrm{~L}^{\text {lo }}$ effective memory CD4 and CD8 T cells (Fig. 3B). The results further showed that BTN2A2 inhibited the activation of CD4 and CD8 T cells.

To investigate whether BTN2A2-Ig protein affects the proliferation of T cells. Stimulate T cells with $5 \mu \mathrm{g} / \mathrm{ml}$ anti-CD3 antibody and culture splenocytes with graded doses of BTN2A2-Ig or control Ig for 3 days. The cells were stained with Ki67, a proliferating cell marker. The expression of $\mathrm{Ki}^{+} 7^{+}$cells in $\mathrm{CD} 4^{+}$or $\mathrm{CD}^{+} \mathrm{T}$ cells was analyzed by flow cytometry. As shown in Fig. 3C, different doses of BTN2A2-Ig protein have inhibitory effects on $\mathrm{CD}^{+}$and $\mathrm{CD} 8^{+} \mathrm{T}$ cells induced by a-CD 3 and are dose-dependent. In conclusion, our data confirmed that BTN2A2 inhibits TCR-mediated activation and proliferation of CD4 and CD8 T cells in vitro.

Then we explored the effects of BTN2A2-Ig protein on Th1 and Th17 cytokine-producing and the differentiation of macrophages in vitro. Spleen cells from C57BL/6 mice were incubated on a 96-well plate pre-coated with $1 \mu \mathrm{g} / \mathrm{ml}$ anti-CD3 antibody and the specified dose of BTN2A2-Ig or control Ig $(10 \mu \mathrm{g} / \mathrm{ml})$. We first examined Th1 or Th17 cytokine-producing. As shown in (Supplementary Fig. 2A-D), BTN2A2-Ig protein reduced Th1 and Th17 cytokine production. Next, we examined whether BTN2A2-Ig affects macrophage polarization in vitro. Our results suggest that BTN2A2-Ig protein reduced the percentage of CD206 ${ }^{\text {lo }} \mathrm{MHCII}{ }^{\mathrm{hi}} \mathrm{M} 1 \mathrm{macrophages}$ but increased the percentage of CD206 ${ }^{\text {hi }} \mathrm{MHCII}^{\mathrm{lo}} \mathrm{M} 2$ macrophages in vitro (Supplementary Fig. 2E,F).

Administration of BTN2A2-Ig fusion protein ameliorates CIA in mice. Having demonstrated that BTN2A2-Ig inhibits T cell activation and proliferation in vitro, we examined whether BTN2A2-Ig could treat autoimmune arthritis. Establishment of CIA model (a flowchart for the generation of CIA model mice is provided in Fig. 4A): immunization with bovine type II collagen and CFA on day 0 and booster immunization with bovine type II collagen and IFA on 21st day, after booster immunization the Mouse slowly developed joint erythema and clinical scores started to increase, with peak incidence when the scores reached 8 on 56 th 

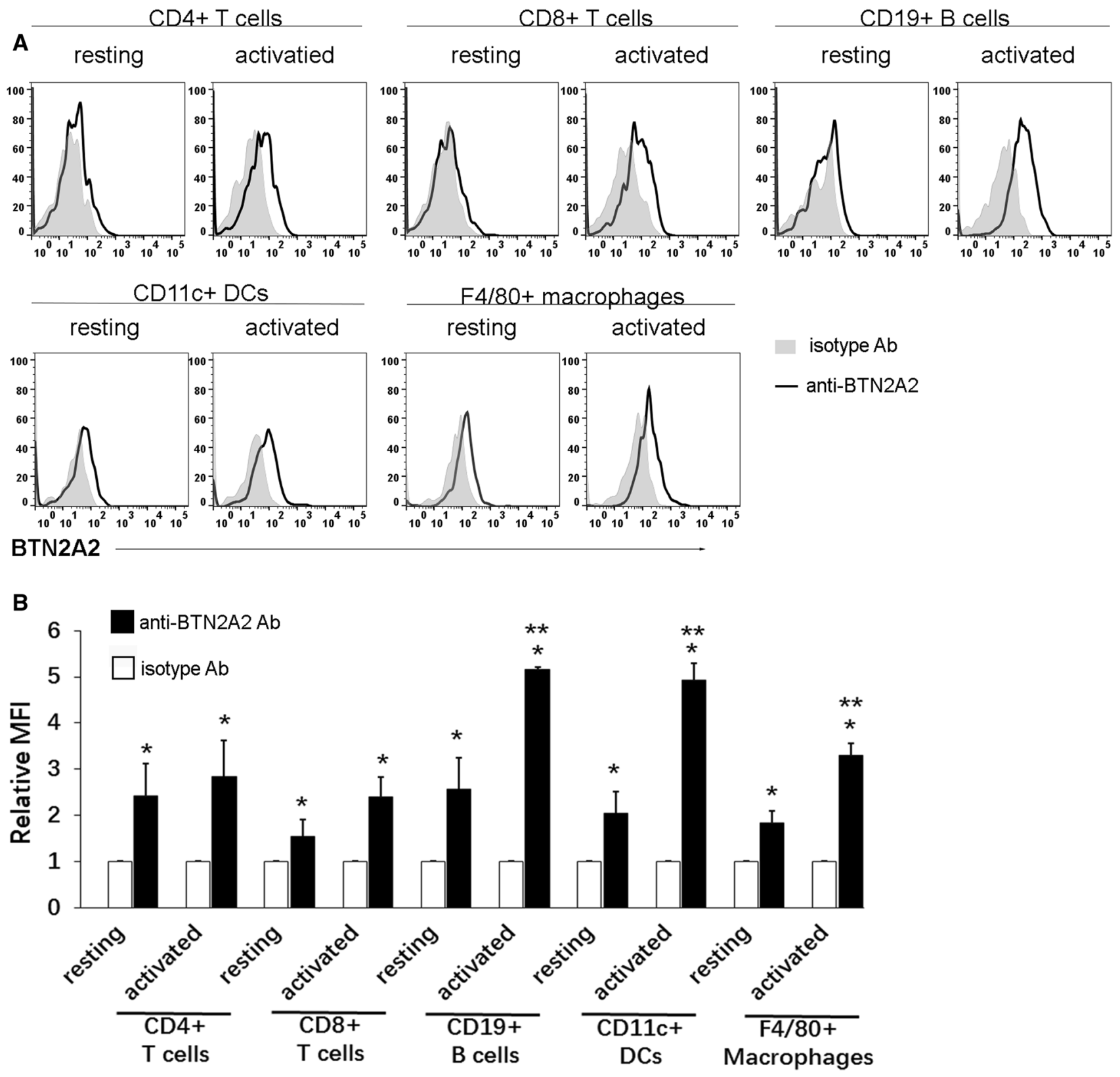

Figure 1. The expression pattern of BTN2A2 protein on immune cells. (A) Splenocytes from C57BL/6 mice that were freshly harvested were used for resting immune cells. To activate $\mathrm{T}$ cell, splenocytes were incubated with anti-CD3 antibody $(1 \mu \mathrm{g} / \mathrm{ml})$ for 3 days. To activate B cells, DCs, monocytes and macrophages, splenocytes were stimulated with LPS $(5 \mu \mathrm{g} / \mathrm{ml})$ for 3 days. The resting and activated immune cells were stained with antiBTN2A2 or isotype antibody as well as anti-CD4, CD8, CD19, CD11c or F4/80 antibody to identify immune cells. The cells were analyzed for BTN2A2 protein expression by flow cytometry. Representative flow cytometric profiles, and (B) Statistical analysis for the expression levels BTN2A2 on immune cells. Data are presented as relative fluorescence intensity (RFI) for the cells stained with antiBTN2A2 antibody versus cells stained with isotype antibody. ${ }^{\star} \mathrm{P}<0.05$ compared with isotype antibody. ${ }^{*} \mathrm{P}<0.05$ compared with resting cells. The data are representative of three independent experiments with similar results ( $\mathrm{n}=3$ each experiment).

day(Fig. 4B), in which the mice were randomly divided and injected intraperitoneally (i.p.) with either control Ig or BTN2A2-Ig protein $(15 \mu \mathrm{g} /$ each mouse) two times per week for 4 weeks. We can see from Fig. $4 \mathrm{~B}$ that the clinical scores of the mice gradually decreased during the process of treatment from 56th day to 84th day and tended to be moderate. The representative images of the hind paws are shown in Fig. 4C. Untreated normal mice were also used as a control. Statistical analysis shows that BTN2A2-Ig decreased the mean hind paw diameter, as compared to control Ig treatment group (Fig. 4D).

The rear paws were harvested from the mice on day 84 and subjected to histological examination. H\&E staining of arthritic paw joints from control Ig-treated CIA mice showed severe infiltration of mononuclear cells and synovial hyperplasia (Fig. 4E). In contrast, BTN2A2-Ig treatment significantly reduced these features (Fig. 4E). 
A

CD4+ T cells

CD8+ T cells

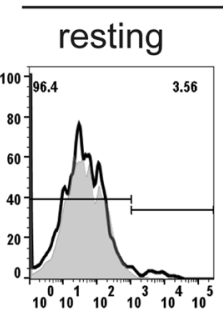

activated
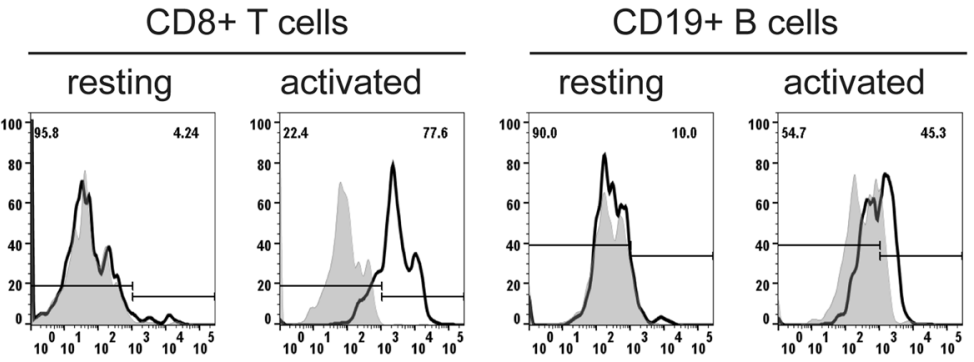

BTN2A2 receptot
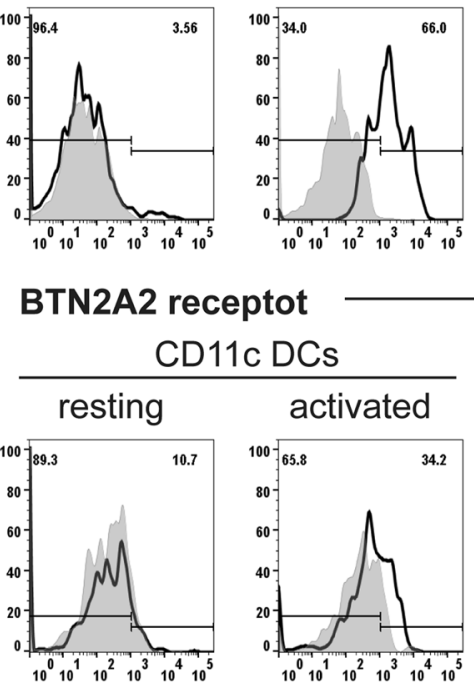

$101010^{2} 10^{3} 10^{4} 10^{5}$

D11c DCs

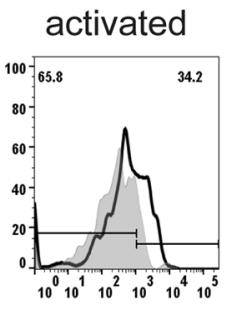

F4/80+macrophages

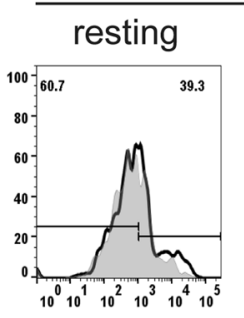

\section{activated}

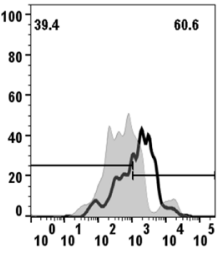

Control Ig

- BTN2A2-Ig

\section{BTN2A2 receptot}

B
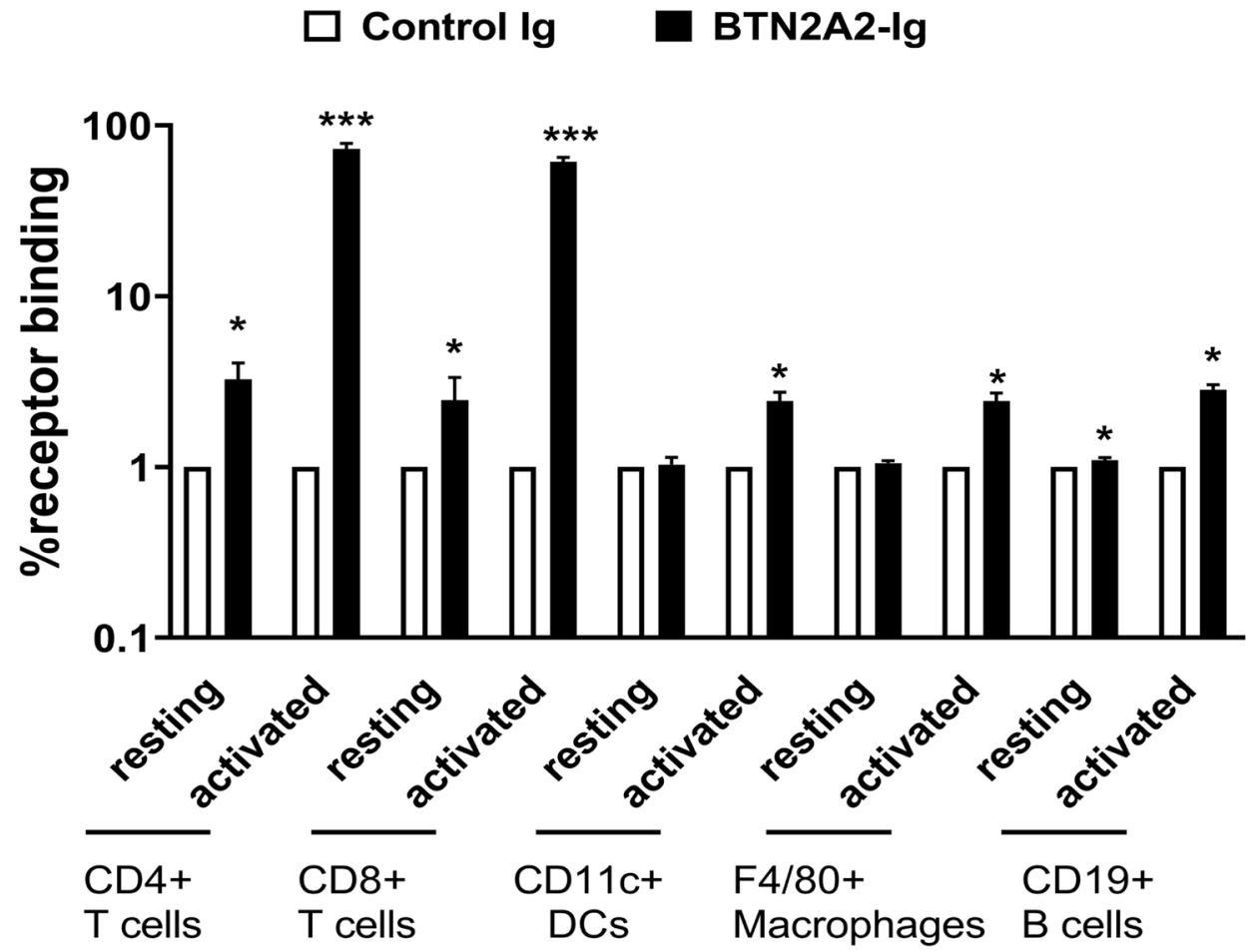

Figure 2. The expression pattern of the putative BTN2A2 receptor on immune cells. Resting and activated immune cells were prepared as Fig. 1. The immune cells were incubated with biotinylated BTN2A2-Ig or control Ig protein for $4 \mathrm{~h}$, followed by $\mathrm{PE}$ conjugating streptavidin and antibodies against CD4, CD8, CD11c or F4/80 or CD19. (A) Representative flow cytometric profiles and (B) statistical analysis showing the binding of BTN2A2-Ig or control Ig to resting and activated immune cells. Data are presented as the percentage of cell binding of BTN2A2-Ig versus control Ig. ${ }^{*} \mathrm{P}<0.05$ compared with control Ig. ${ }^{* *} \mathrm{P}<0.05$ compared with resting cells. The data are representative of three independent experiments with similar results. $(\mathrm{n}=3$ each experiment). 
$\mathbf{A}$ - control lg -BTN2A2-lg
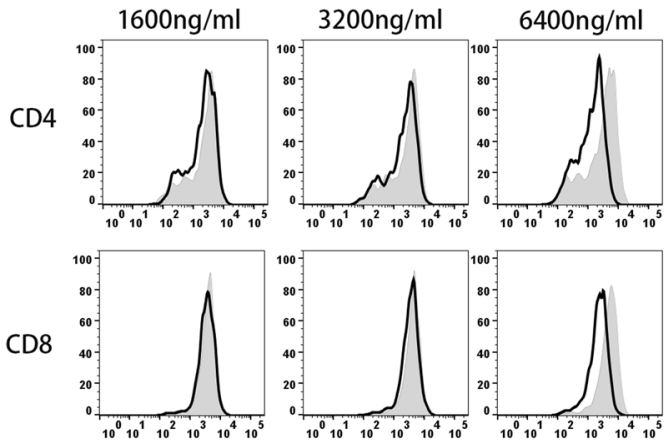
CD69
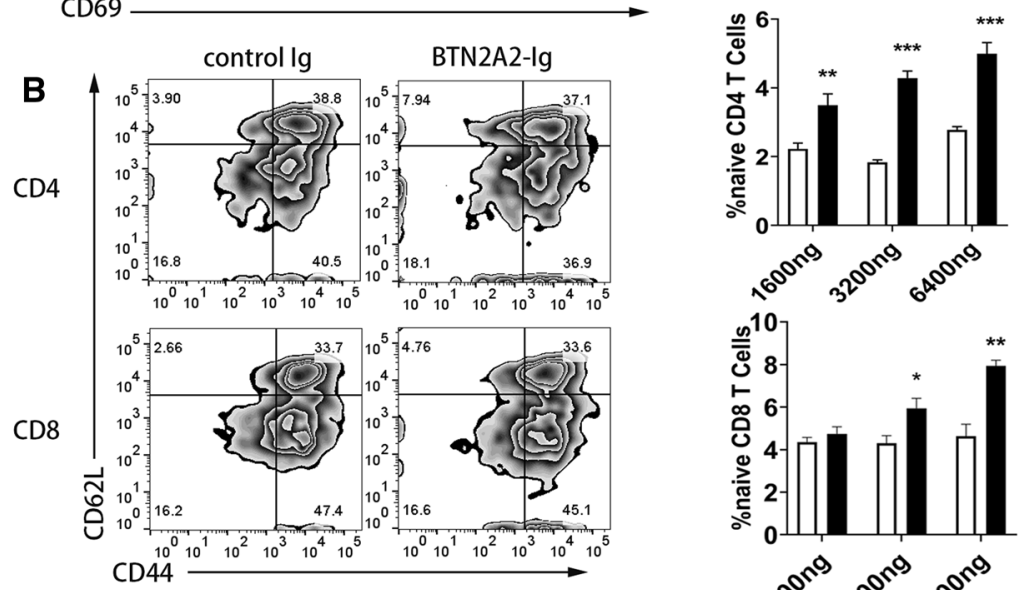

BTN2A2-Ig
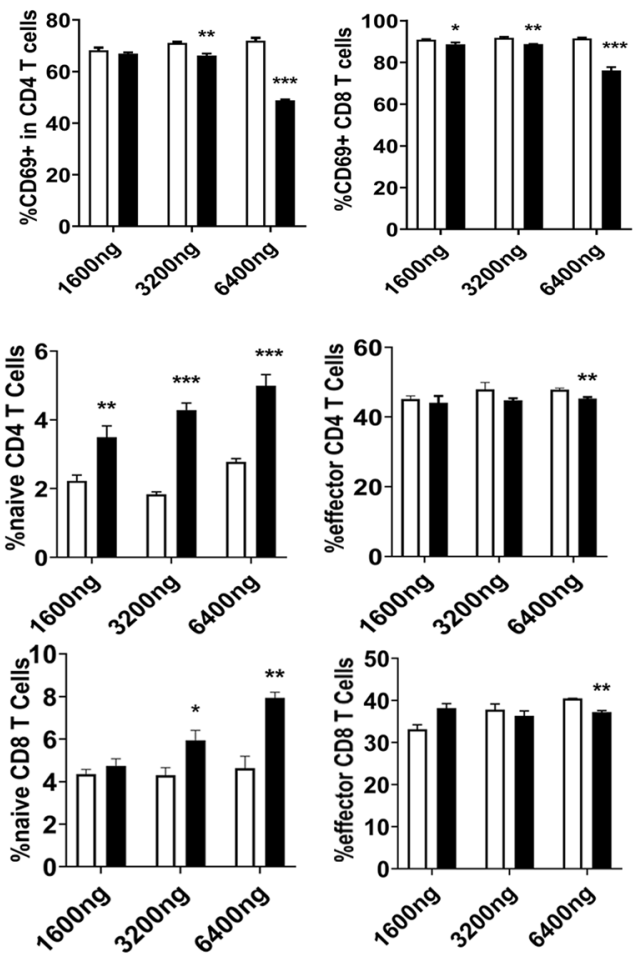

$\mathbf{C}$
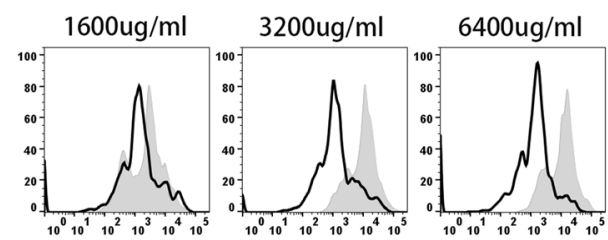

CD8
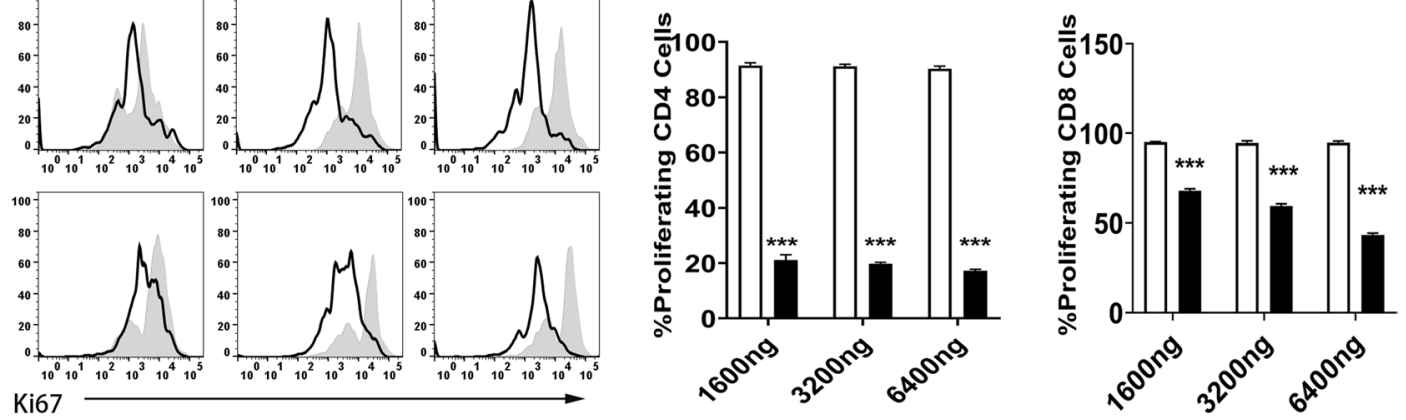

Figure 3. The effects of BTN2A2-Ig protein on murine T cell activation and proliferation in vitro. Splenocytes from C57BL/ 6 mice were incubated on 96-well plate precoated with $0.5 \mu \mathrm{g} / \mathrm{ml}$ of anti-CD3 antibody and the indicated dose of BTN2A2-Ig or control Ig. The cells were analyzed for (A) the expression of CD69 $18 \mathrm{~h}$ later and $(\mathrm{B})$ the percentages of CD $44^{\text {lo }} \mathrm{CD} 62 \mathrm{~L}^{\text {hi }}$ naïve and CD44 ${ }^{\text {hi }} \mathrm{CD} 62 \mathrm{~L}^{\text {lo }}$ effective memory CD4 and CD8 T cells $72 \mathrm{~h}$ later, and $(\mathbf{C})$ the expression of Ki67 by CD4 or CD8 positive T cells $72 \mathrm{~h}$ later. The data are representative of three independent experiments with similar results. $\left(\mathrm{n}=3\right.$ each experiment) ${ }^{\star} \mathrm{P}<0.05,{ }^{\star \star} \mathrm{P}<0.01$ and ${ }^{* * *} \mathrm{P}<0.001$, compared with control Ig.

in poor pink color, whereas BTN2A2-Ig-treated mice had significantly reduced cartilage destruction (Fig. 4G,H). Taken together, our results suggest that in vivo administration of BTN2A2-Ig protein attenuates established CIA.

BTN2A2-Ig inhibits T cell activation and proliferation but increases the proportion of Tregs in $\mathrm{CIA}$ mice. We then analyzed T cell activation and proliferation in the control Ig and BTN2A2-Ig treated CIA mice. BTN2A2-Ig treatment significantly reduced the expression of CD69 by CD4 and CD8 T cells (Fig. 5A,B), increased the percentages of $\mathrm{CD} 44^{\mathrm{lo}} \mathrm{CD} 62 \mathrm{~L}^{\text {hi }}$ naive $\mathrm{CD} 4$ and $\mathrm{CD} 8 \mathrm{~T}$ cells but decreased the percentages of $\mathrm{CD} 44^{\text {hi }} \mathrm{CD} 62 \mathrm{~L}^{\text {lo }}$ effective memory CD4 and CD8 T cells (Fig. 5C,D). BTN2A2-Ig treatment also inhibited CD4 and CD8 T cell proliferation as determined by CFSE dilution assay (Fig. 5E,F) and Ki67 staining (Fig. 5G,H). Our results suggest that BTN2A2-Ig treatment inhibits the activation and proliferation of T cells in vivo, consistent with our in vitro data (Fig. 3), 
A

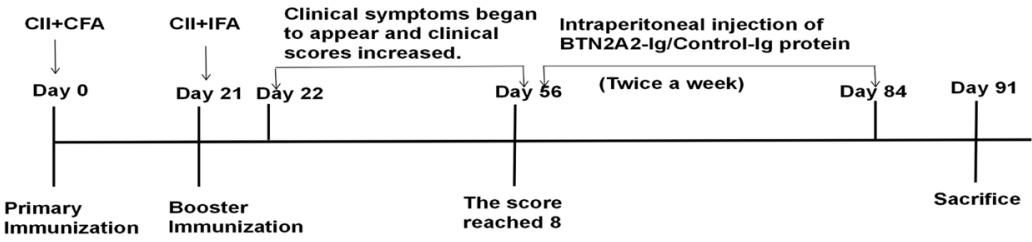

B

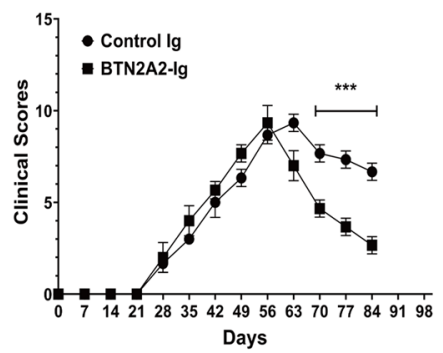

D

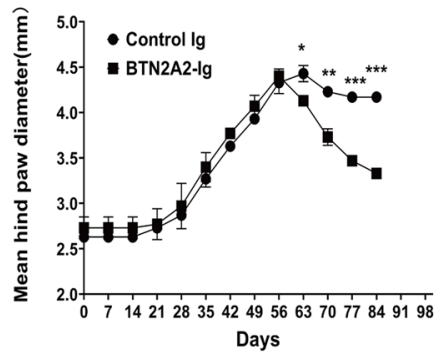

E

HE

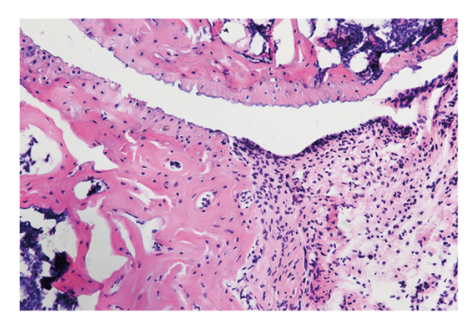

G

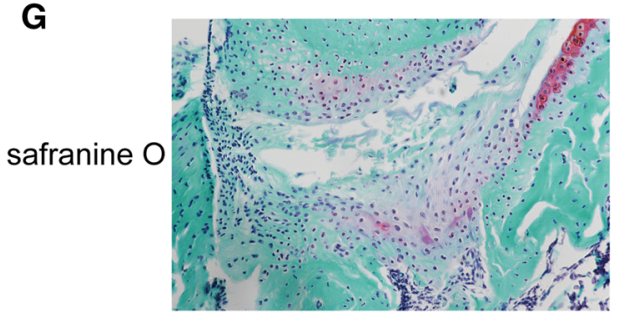

C

untreatd
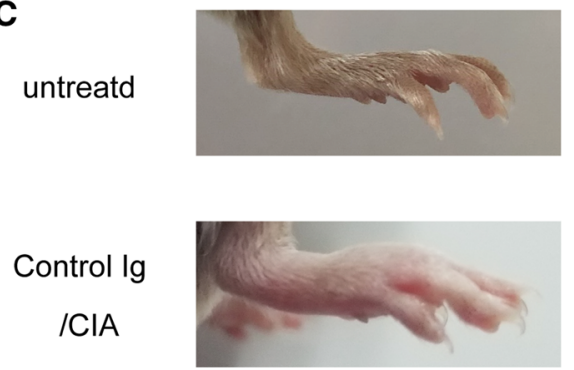

Day 25 of Control Ig treatment

BTN2A2-Ig ICIA

Day 25 of BTN2A2-lg treatment

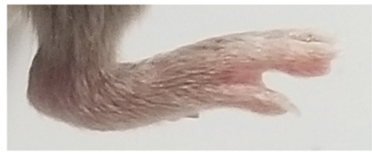

Figure 4. Administration of BTN2A2-Ig alleviates CIA in mice. Male 6-8-week-old DBA/1J mice were immunized with $200 \mu \mathrm{g}$ of bovine collagen II emulsified in CFA on day 0, and rechallenged with bovine collagen II emulsified in IFA on 21 days. When clinical scores were reached 8, The mice were injected i.p. with $15 \mu \mathrm{g}$ BTN2A2-Ig or control Ig protein two times per week for 4 weeks. CIA development was monitored over time. (A) A flowchart for the generation of CIA model mice, (B) CIA clinical scores, (C) representative images of hind paws from control Ig- or BTN2A2-Ig protein-treated CIA mice and untreated normal mice, and (D) statistical analysis of the thickness of hind paws. (E-H) The rear paws were harvested from the mice on day 84. (E,F) H\&E staining of (E) the sections of metatarsophalangeal joint from control Ig- or BTN2A2-Ig-treated CIA mice, and (F) pathological scores are shown. $(\mathbf{G}, \mathbf{H})$ Safranin O-fast green staining of $(\mathbf{G})$ representative hind paws, and (H) pathological scores are shown. The data are representative of three independent experiments $(n=6$ each experiment each group) with similar results. 
A

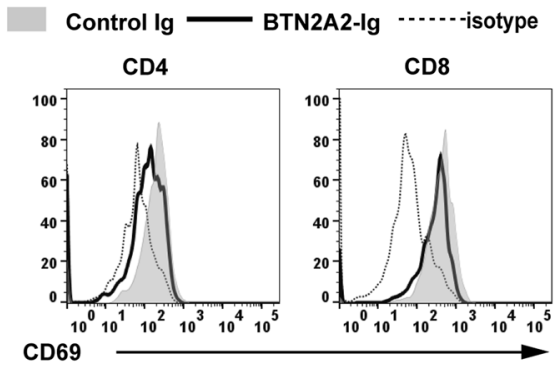

C

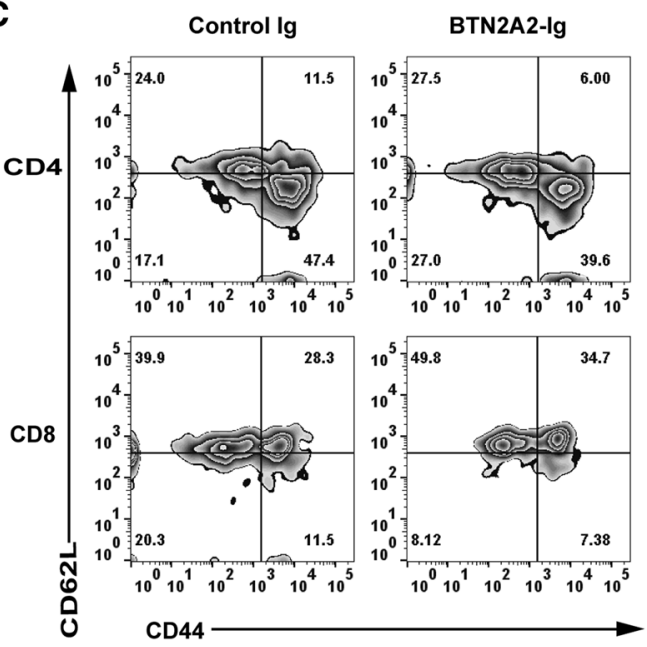

E

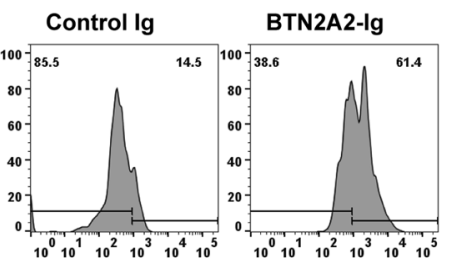

$\mathbf{F}$

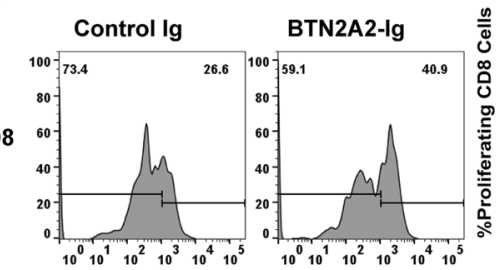

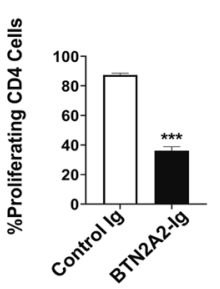

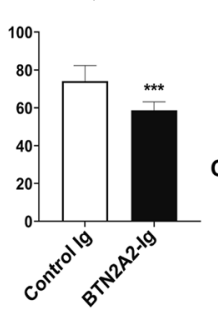

BTN2A2-Ig

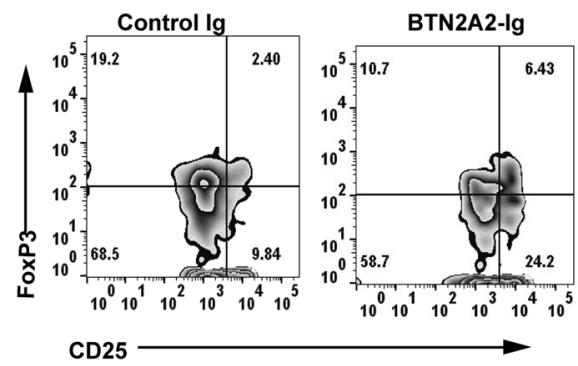

B Control Ig

BTN2A2-lg $\square$ isotype
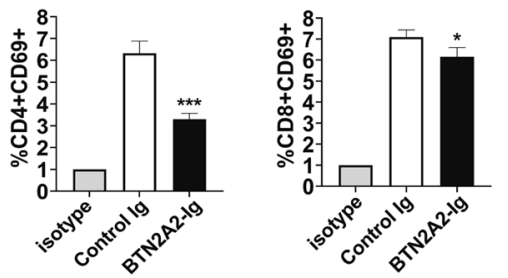

D
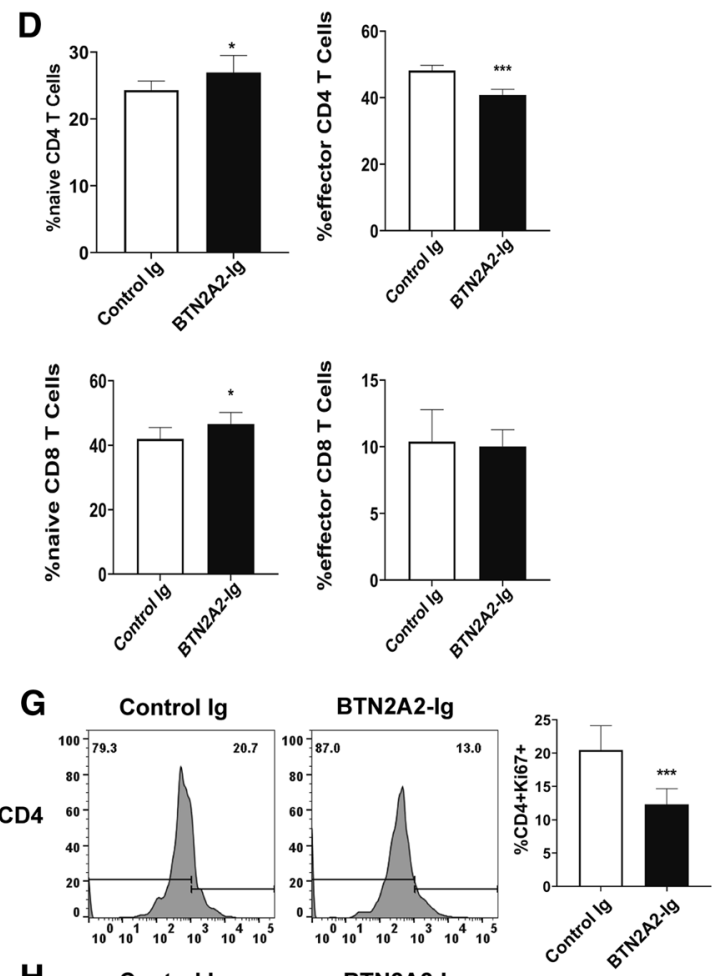

H
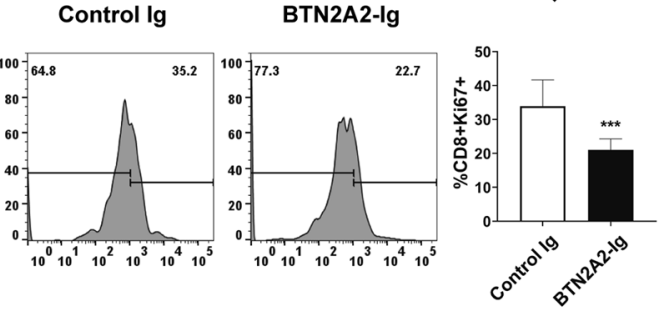

$\mathbf{J}$

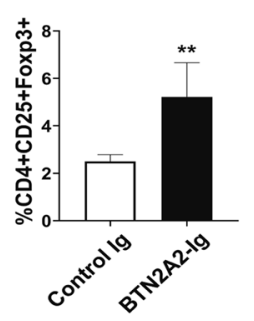

Figure 5. BTN2A2-Ig inhibits T cell activation and proliferation in CIA mice. DBA/1J CIA mice were treated with BTN2A2-Ig or control Ig as in Fig. 4. The spleens were harvested 35 days later. Spleen cells were stained with anti-CD69 or isotype antibodies as well as anti-CD4, CD8 antibody to identify activated cells. The splenocytes were analyzed for $(\mathbf{A}, \mathbf{B})$ the expression of CD69 by CD4 and CD8 T cells, $(\mathbf{C , D})$ the percentages of $\mathrm{CD} 44^{\mathrm{lo}} \mathrm{CD} 62 \mathrm{~L}^{\text {hi }}$ naive and $\mathrm{CD} 44^{\mathrm{hi}} \mathrm{CD} 62 \mathrm{~L}^{\mathrm{lo}}$ effector memory in $\mathrm{CD} 4$ and $\mathrm{CD} 8 \mathrm{~T}$ cells, and $\mathrm{T}$ cell proliferation by (E,F) CFSE dilution assay and (G,H) Ki67 staining. (I,J) The splenocytes were also analyzed for the percentages of $\mathrm{CD} 25^{+} \mathrm{FoxP}^{+} \mathrm{CD}_{4}{ }^{+}$Tregs. The data are expressed as the mean $\pm \mathrm{SD}$ and representative of three independent experiments with similar results. ( $\mathrm{n}=6$ each experiment each group) ${ }^{\star} P<0.05,{ }^{* *} P<0.001$ compared with control-Ig. 
Since Tregs play a key role in immune tolerance induction and $\mathrm{CD} 4{ }^{+} \mathrm{CD} 25^{+} \mathrm{FoxP} 3^{+}$cells are the most profoundly characterized Tregs ${ }^{29}$, we then evaluated $\mathrm{CD} 4{ }^{+} \mathrm{CD} 25^{+} \mathrm{FoxP}^{+}$Tregs. We found that BTN2A2-Ig treatment increased the percentage of Tregs in the spleen (Fig. 5I,J).

BTN2A2-Ig reduces Th1 and Th17 cytokine production in CIA mice and inhibits CII-specific T cell proliferation and cytokine production. We also analyzed cytokine production in the CIA mice. We first examined Th1 or Th17 cytokine-producing T cells in the spleen. As shown in (Fig. 6A-D), BTN2A2-Ig treatment led to reduced percentages of TNF- $\alpha$ and IL-17A-producing CD4 and CD8 T cells. We then examined the levels of Th1/Th17 cytokines in the serum. BTN2A2-Ig treatment also reduced the contents of TNF- $\alpha$, IFN- $\gamma$ and IL-17A in the serum (Fig. 6E).

We investigated whether BTN2A2-Ig modulates CII-specific T cell responses, the purpose of which is to detect antigen-specific T cell proliferation and cytokine production. Splenocytes from control Ig or BTN2A2Ig-treated mice were isolated and stimulated with CII in vitro for $72 \mathrm{~h}$. T cell proliferation was analyzed by CFSE dilution assay or Ki67 staining. As shown in (Fig. 6F,G), BTN2A2-Ig treatment led to reduced CD4 and CD8 T cell proliferation.

We then analyzed the cytokine contents in the supernatants of the CII-stimulated cultured cells. Splenic cells from the control Ig-treated mice produced high levels of IFN- $\gamma$ and IL-17A in response to CII, whereas the production of IFN- $\gamma$ and IL-17A was greatly reduced from the cells of BTN2A2-Ig-treated mice (Fig. 6H). Taken together, the results suggest that BTN2A2-Ig reduces CII-specific T cell proliferation and Th1 and Th17 cytokine production.

BTN2A2-Ig reduces proinflammatory M1 macrophages but increases anti-inflammatory M2 macrophages in CIA mice. Macrophages can be divided into two distinct subsets, the classically activated $\mathrm{M} 1$ and alternatively activated M2 macrophages ${ }^{30}$. M1 macrophages are proinflammatory, whereas M2 macrophages are anti-inflammatory. Since macrophages also express the BTN2A2 receptor, we analyzed macrophages in the BTN2A2-Ig-treated mice. BTN2A2-Ig reduced the percentage of CD206 ${ }^{\text {lo }}$ MHCII ${ }^{\text {hi }}$ M1 macrophages but increased the percentage of $\mathrm{CD} 2 \mathrm{O} 6{ }^{\mathrm{hi}} \mathrm{MHCII}^{10} \mathrm{M} 2$ macrophages (Fig. 7A,B). Furthermore, BTN2A2-Ig reduced the percentage of TNF- $\alpha$ producing $\mathrm{F} 4 / 80^{+}$macrophages (Fig. $7 \mathrm{C}, \mathrm{D}$ ). The results suggest that the CIA reduction by BTN2A2 may also be mediated by macrophages.

\section{Discussion}

We have shown here that BTN2A2 is expressed on dendritic cells, macrophages and B cells, and its expression levels were significantly upregulated upon activation. The BTN2A2 putative receptor is expressed on activated CD4 and CD8 T cells at high levels and on activated dendritic cells, macrophages and B cells at low levels. BTN2A2-Ig protein inhibits the activation and proliferation of CD4 and CD8 T cells in vitro. Administration of BTN2A2-Ig protein ameliorates established CIA, which is related to reduced activation and proliferation of CD4 and CD8 T cells, decreased production of IFN- $\gamma$ and IL-17A, and reduced inflammatory M1 macrophages but increased anti-inflammatory M2 macrophages. To our knowledge, this is the first time to show that in vivo administration of BTN2A2-Ig protein can attenuate autoimmune arthritis in mice.

$\mathrm{T}$ cell inhibitory molecules are usually expressed on APCs, which is involved in the regulation of T cell activation and proliferation. We show here that BTN2A2 is also expressed on APCs especially on activated DCs, macrophages and $\mathrm{B}$ cells, consistent with its role in limiting $\mathrm{T}$ cell activation and proliferation in inflammation. We have also shown that BTN2A2-Ig protein inhibits T cell activation as indicated by reduced expression of CD69 and increased proportion of naive T cells but decreased effector T cells after BTN2A2-Ig treatment. Furthermore, BTN2A2-Ig inhibits T cell proliferation. Our results are consistent with the data that the BTN2A2 putative receptor is expressed on activated T cells. The mechanisms by which BTN2A2 inhibits T cell functions are likely related to the inhibition of TCR signaling molecules including CD3s, Zap70, and Erkl/2, as well as PI3K and Akt signaling ${ }^{19}$.

BTN2A2-Ig treatment significantly reduces CIA clinical and pathological scores. T cell activation and proliferation in the BTN2A2-Ig-treated CIA mice were significantly reduced, which is agreement with our in vitro data. Furthermore, BTN2A2-Ig inhibits Th1/Th17 cytokine production of CII-specific autoreactive T cells. All these are likely responsible for the attenuated CIA by BTN2A2-Ig.

Tregs can inhibit effector $\mathrm{T}$ cells and are critical in immune tolerance induction ${ }^{29}$. We also found that $\mathrm{CD}^{+} \mathrm{CD} 25^{+} \mathrm{FoxP}^{+}$Tregs were increased in the BTN2A2-Ig-treated CIA mice. Tregs can be divided into natural and induced Tregs; the former develops in the thymus, whereas the latter develops in the periphery. Thymic epithelial cells (TECs) play a key role in natural Treg development. It has been reported that BTN2A2 is expressed on TECs ${ }^{21}$. It is possible that BTN2A2 is involved in the production of natural Tregs by its expression on TECs. Because BTN2A2 inhibits Erk1/2 and Akt signaling in T cells and because inhibition of these signaling increases the production of induced Tregs, it is possible that BTN2A2 also increases the production of induced Tregs.

BTN2A2-Ig-treated CIA mice also have reduced IL-17A producing T cells in the spleen and decreased IL$17 \mathrm{~A}$ in the serum. It has been reported that Foxp3 can repress the expression of the IL-17 gene $\mathrm{g}^{31,32}$. It is possible that the reduced Th17 cells in the BTN2A2-Ig-treated CIA mice is due to repression of IL-17 gene expression by Foxp 3 or by induction of Tregs which suppress Th17 activation and proliferation ${ }^{19}$.

We have shown that the proportion of inflammatory M1 macrophages was decreased, whereas that of anti -inflammatory M2 macrophages was increased in BTN2A2-Ig-treated CIA mice, indicating that BTN2A2 also affects macrophages. It is likely that the effects of BTN2A2-Ig on macrophages also play a role in the ameliorated CIA. Although we have shown that the BTN2A2 putative receptor is expressed on macrophages, whether BTN2A2 directly affects macrophages remains to be investigated. 

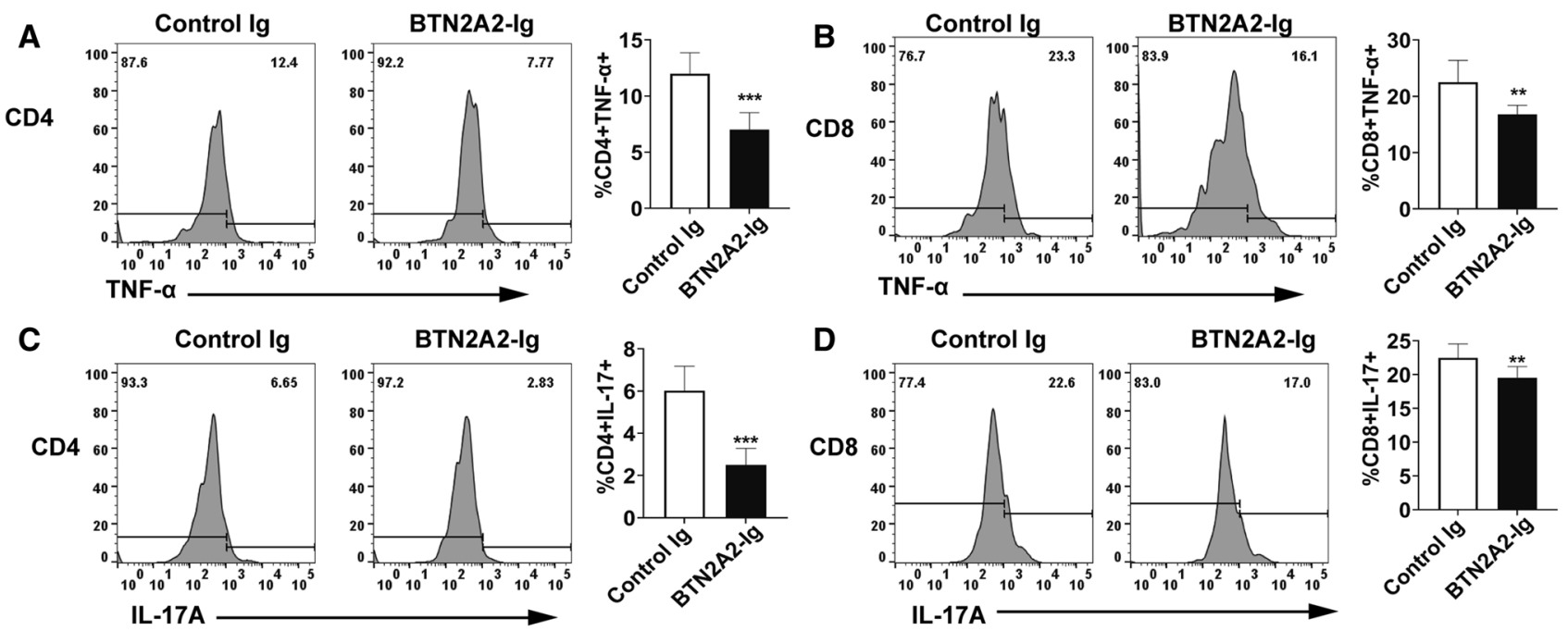

E
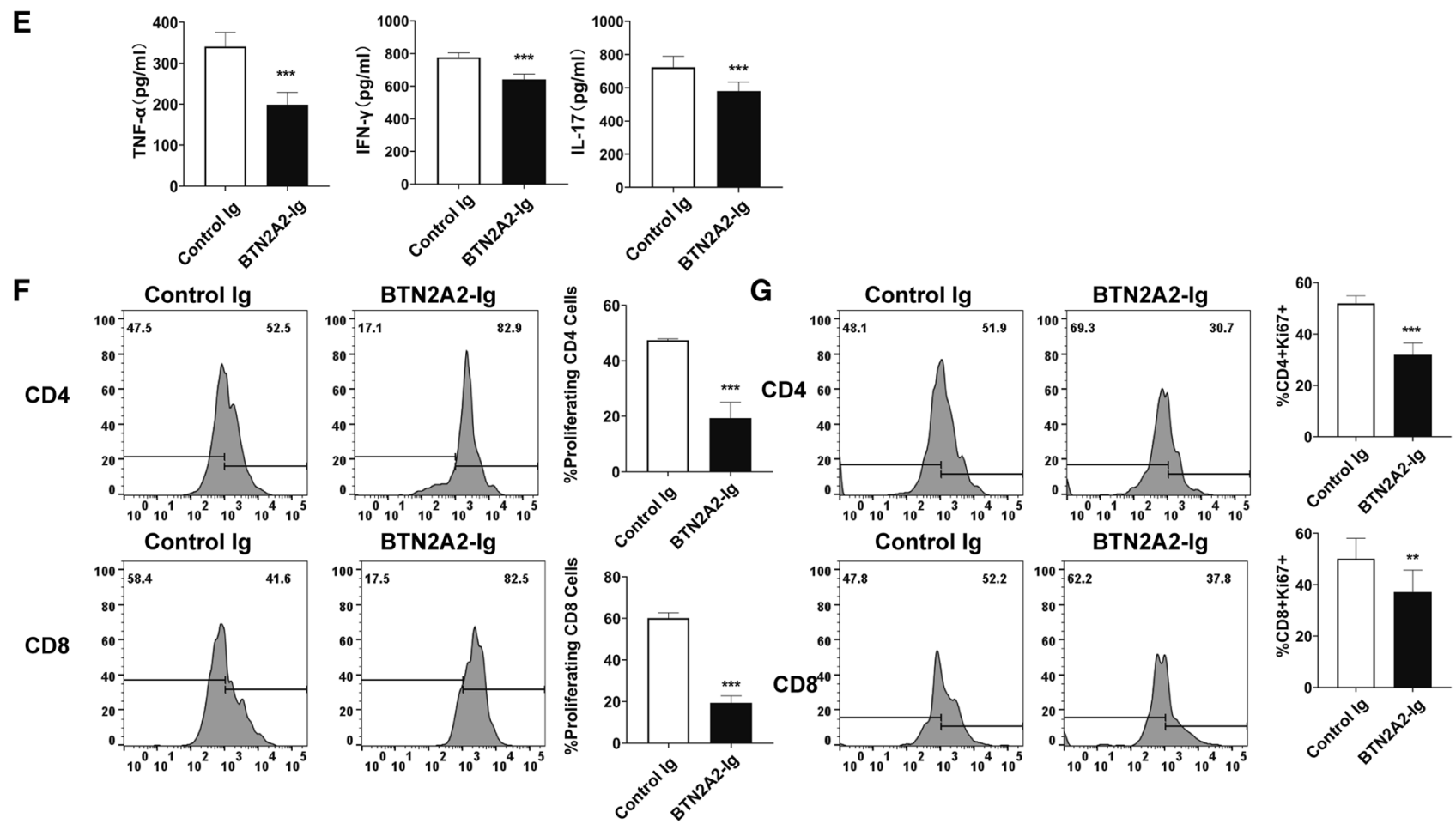

H
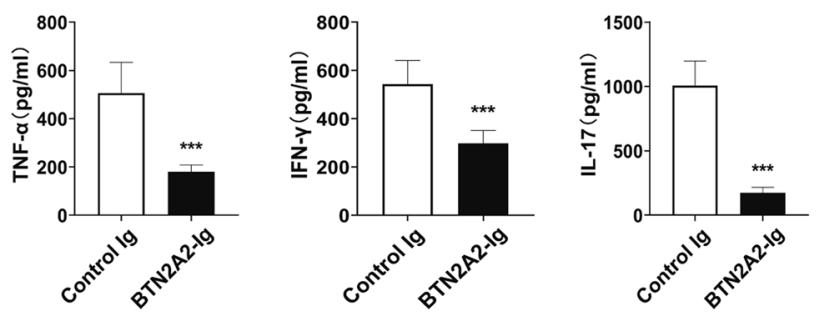

Figure 6. BTN2A2-Ig reduces Th1 and Th17 cytokine production in CIA mice. DBA/1J CIA mice were treated with mBTN2A2-Ig or control Ig as in Fig. 5. The percentages of cytokine-producing CD4 and CD8 T cells were analyzed by flow cytometry. The representative flow cytometric profiles and statistics analysis of $(\mathbf{A}, \mathbf{B})$ TNF- $\alpha^{+}$ or (C,D) IL-17A ${ }^{+}$T cells. (E) The levels of TNF- $\alpha$, IFN- $\gamma$, or IL-17A in the serum were measured by ELISA. (F-H) Splenocytes from CIA mice treated with BTN2A2-Ig or control Ig were cultured with $30 \mu \mathrm{g} / \mathrm{ml}$ of CII in vitro for $72 \mathrm{~h}$. (F,G) T cell proliferation was analyzed by (F) CFSE dilution assay or (G) Ki67 staining. (H) The levels of IL-17A, TNF- $\alpha$ and IFN- $\gamma$ in the supernatant were analyzed by ELISA. The data are expressed as the mean \pm SD and representative of three independent experiments with similar results. $(n=6$ each experiment each group $)^{\star * *} P<0.001$ compared with control Ig-treated mice. 
A

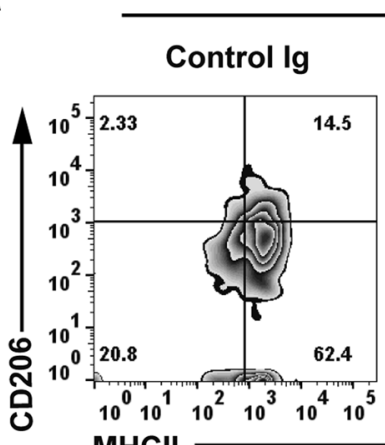

$\mathrm{MHCII}$
F4/80+macrophages

BTN2A2-Ig

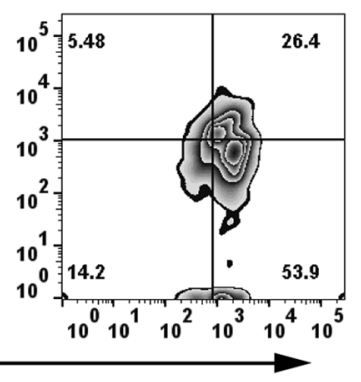

F4/80+macrophages

C

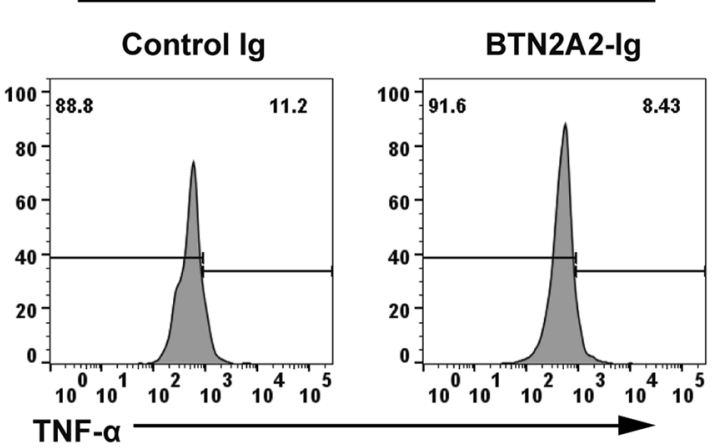

B
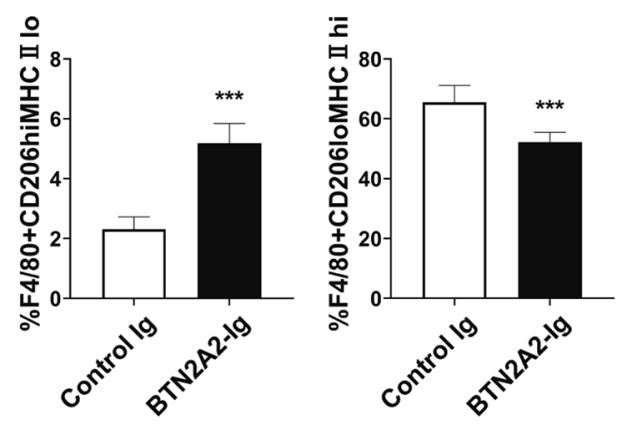

D

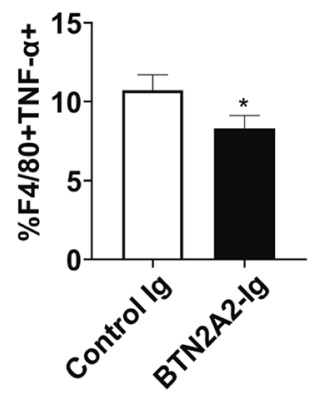

Figure 7. BTN2A2-Ig reduces M1 macrophages but increase M2 macrophages in vivo. Splenocytes from CIA mice treated with BTN2A2-Ig or control Ig as in Fig. 5. Cells were analyzed for $(\mathbf{A}, \mathbf{B})$ the percentages of F4/80 ${ }^{+} \mathrm{CD} 206^{\text {hi }} \mathrm{MHCII}^{\mathrm{lo}} \mathrm{M} 2$ and F4 $/ 80^{+} \mathrm{CD} 206^{\mathrm{lo}} \mathrm{MHCII}{ }^{\text {hi }} \mathrm{M} 1$, as well as (C,D) the percentages of TNF- $\alpha$ producing $\mathrm{F} 4 / 80^{+}$macrophages by flow cytometry. Data are shown as mean $\pm \mathrm{SD}$ from one out of 3 independent experiments with similar results. $\left(\mathrm{n}=6\right.$ each experiment each group) ${ }^{\star *} \mathrm{P}<0.01,{ }^{* * *} \mathrm{P}<0.001$ compared with control Ig-treated mice.

In summary, we have shown that BTN2A2-Ig protein inhibits T cell function in vitro and in vivo. Administration of BTN2A2-Ig protein attenuates established CIA. Our results suggest that BTN2A2-Ig protein has the potential to be used in the treatment of autoimmune disease including RA.

\section{Materials and methods}

All methods were carried out in accordance with the relevant guidelines and regulations.

Cloning and purification of mBTN2A2. The extracellular domain of mBTN2A2 (aa30-246) were cloned and insert into a pCMV6-AC-FC-S expression vector containing the constant region of mouse IgG2a (Origin Gene, Rockville, MD). The vector was transfected into HEK-293 cells. The fusion protein was purified from the supernatant using Protein G Sepharose 4 Fast Flow resin (GE Healthcare, Buckinghamshire, UK) according to the manufacturer's instructions. The purified protein was verified by SDS-PAGE, Coomassie staining, and western blotting. The protein was quantified using the Pierce BCA Protein Assay Kit (Pierce, Rockford, IL). The endotoxin level of the recombinant protein was $<0.01 \mathrm{EU} / \mathrm{ml}$ pig- 1 of purified protein as determined by the endpoint chromogenic LAL test. Control Ig (recombinant mouse IgG2a Fc protein) was purchased from BXCell (West Lebanon, $\mathrm{NH})^{30}$.

SDS-PAGE and Western Blot. Purified mBTN2A2-Ig was loaded on a $12 \%$ SDS-PAGE, stained with Coomassie blue or transferred to a polyvinylidene fluoride membrane. The protein containing membrane was incubated with HRP conjugated anti-mouse IgG2 antibody, or anti-mBTN2A2 antibody (Novus Biologicals, Littleton, CO) followed by HRP conjugated second antibody, and then developed with Super Signal West Pico chemiluminescent Substrate (Thermo Fisher Scientific, Waltham, MA, USA) ${ }^{33}$.

Mice. DBA/1 and C57BL/6 mice were purchased from the Gempharmatech Co. Ltd (Nanjing, China). The mice were maintained in specific pathogen-free rooms and used in accordance with protocols approved by the Institutional Animal Care and Use Committee of the Guizhou Medical University (NO:1900035). Furthermore, the study was carried out in compliance with the ARRIVE guidelines. 
Induction and assessment of CIA. Male 6-8 weeks DBA/1 mice were immunized with 200 pg of bovine collagen II (Chondrex Inc., cat. no. 2002-2) emulsified in an equal volume of Freund's complete adjuvant (CFA) at two injection sites of the base of the tails on day 0 , and a boost injection of bovine collagen II emulsion in Freund's incomplete adjuvant (IFA) on 21 days. The mice were examined for signs of arthritis 2 times a week. When clinical scores were up to 8, the mice were injected i.p. with 15 pig BTN2A2-Ig or control Ig protein two times per week for 4 weeks. CIA development was monitored over time. The swelling of four paws was graded from 0 to 4 as follows ${ }^{34}$ : grade 0 , no evidence of erythema and swelling; grade 1, erythema and mild swelling confined to the tarsals or ankle joint; grade 2, erythema and mild swelling extending from the ankle to the tarsals; grade 3 , erythema and moderate swelling extending from the ankle to metatarsal joints; and grade 4, erythema and severe swelling encompass the ankle, foot and digits, or ankylosis of the limb ${ }^{2}$. Each paw was graded, and the four scores were totaled so that the maximal scores per mouse was 16 .

Histopathology. Limbs were fixed in 4\% paraformaldehyde and decalcified with 31.5\% (v/v) formic acid and $13 \%(\mathrm{w} / \mathrm{v})$ sodium citrate. The paraffin sections were stained with H\&E. Subsequently, the evaluation of synovitis, pannus formation, as well as bone and cartilage destruction were determined by a graded scale as follows: grade 0 , no signs of inflammation; grade 1 , mild inflammation with hyperplasia of the synovial lining without cartilage destruction; grades 2 through 4, increasing degrees of inflammatory cell infiltrate and cartilage/bone destruction. Sections were also stained with $0.1 \%$ Safranin O for detection of cartilage proteoglycan and assessed by the Mankin scoring system: matrix staining (0-4), cartilage structure (0-6), cell appearance $(0-3)$ and invasion of the tidemark $(0-1)^{35}$.

In vitro T cell assay. Splenocyte proliferative response was assessed by carboxyfluorescein diacetate succinimidyl ester (CFSE) dilution assay. Splenocytes were labeled with CFSE (Thermo Fisher Scientific, Waltham, MA, USA) and in the presence of BTN2A2-Ig or control Ig for 3 days. The cells were analyzed by flow cytometry.

Flow cytometry analysis. Single-cell suspensions of spleen were stained with fluorochrome-conjugated $\mathrm{Ab}$ proteins as previously described. For intracellular staining, the cells were first permeabilized with $0.25 \%$ Triton X-100 for $20 \mathrm{~min}$ at $4{ }^{\circ} \mathrm{C}$. Fluorochrome-conjugated antibodies were used for direct or indirect staining, including anti-CD4, CD8, CD19, CD11c, F4/80, CD44, CD62L, CD69, CD25, FoxP3, Ki67, CD206 and MHC II (BioLegend, San Diego, CA, USA). Anti-BTN2A2 polyclonal antibody and PE-conjugated secondary antibody were purchased from Novus Biologicals (Littleton, CO, USA) and Abcam (Cambridge, MA, USA). Isotype control antibodies were purchased from Abcam (Cambridge, MA, USA) ${ }^{33}$. BTN2A2-Ig was biotinylated with sulfoNHS-LC-biotin (Thermo Fisher Scientific, Waltham, MA, USA). The samples were analyzed on a FACS Celesta (BD Biosciences). Data analysis was performed using FlowJo software (Ashland, OR, USA).

Intracellular staining. For staining of intracellular TNF-aand IL-17A, splenocytes were stimulated by PMA $(100 \mathrm{ng} / \mathrm{ml})$, ionomycin $(500 \mathrm{ng} / \mathrm{ml})$ and brefeldin $(100 \mathrm{ng} / \mathrm{ml})$ (from Shanghai Selleck Chemicals) for $4 \mathrm{~h}$ at $37^{\circ} \mathrm{C}$, then stained with IL-17 and TNF- $\alpha$ antibody at $4{ }^{\circ} \mathrm{C}$ for $30 \mathrm{~min}$, respectively; finally, the cells were stained with CD4 and CD8 antibody at $4{ }^{\circ} \mathrm{C}$ for $30 \mathrm{~min}$. Cells were analyzed by flow cytometry ${ }^{36}$.

Statistical analysis. All data are presented as the mean \pm SD of at least three independent experiments. According to analysis, GraphPadPrim5 is used as a drawing tool and a secondary assist in statistical analysis tools. P-values were based on the two-sided Student's t-test. $\mathrm{P}<0.05$ was considered to indicate a statistically significant difference.

\section{Data availability}

The date that support the findings of this study are available from the corresponding author upon reasonable request.

Received: 17 March 2021; Accepted: 6 September 2021

Published online: 29 September 2021

\section{References}

1. Behl, T. et al. Exploring the role of polyphenols in rheumatoid arthritis. Crit. Revfood Sci. 61, 1-22 (2021).

2. Brand, D. D., Latham, K. A. \& Rosloniec, E. F. Collagen-induced arthritis. Nat. Protoc. 2, 1269-1275 (2007).

3. Zhu, C. et al. FTY720 inhibits the development of collagen-induced arthritis in mice by suppressing the Recrui ${ }^{\mathrm{tm}} \mathrm{ent}$ of CD4 T lymphocytes. Drug Des. Dev. Ther. 15, 1981-1992 (2021).

4. Brand, D. D., Kang, A. H. \& Rosloniec, E. F. Immunopathogenesis of collagen arthritis. Springer Semin. Immunopathol. 25, 3-18 (2003).

5. Aldridge, J. et al. T helper cells in synovial fluid of patients with rheumatoid arthritis primarily have a Th1 and a CXCR3Th2 phenotype. Arthritis Res. Ther. 22, 245 (2020).

6. Miao, J. et al. CD147 expressed on memory CD4 T cells limits Th17 responses in patients with rheumatoid arthritis. Front Immunol. 11, 545980 (2020).

7. Jiang, Q., Yang, G., Liu, Q., Wang, S. \& Cui, D. Function and role of regulatory T cells in rheumatoid arthritis. Front. Immunol. 12, 626193 (2021).

8. Sarter, K. et al. Btn2a2, a T cell immunomodulatory molecule coregulated with MHC class II genes. J. Exp. Med. 213, 177-187 (2016).

9. Arnett, H. A. \& Viney, J. L. Immune modulation by butyrophilins. Nature reviews. Immunology 14, 559-569 (2014).

10. Lin, Y. et al. Skint8, a novel B7 family-related molecule, negatively regulates T cell responses. J. Immunol. (Baltimore, Md.: 1950). 203, 400-407 (2019). 
11. Abeler-Dörner, L., Wamy, M., Williams, G., Hayday, A. C. \& Bas, A. Butyrophilins: An emerging family of immune regulators. Trends Immunol. 33, 34-41 (2012).

12. Afrache, H., Gouret, P., Ainouche, S., Pontarotti, P. \& Olive, D. The butyrophilin (BTN) gene family: From milk fat to the regulation of the immune response. Immunogenetics 64, 781-794 (2012).

13. Guo, Y. \& Wang, A. Y. Novel immune check-point regulators in tolerance maintenance. Front. Immunol. 6, 421 (2015).

14. Rhodes, D. A., Reith, W. \& Trowsdale, J. Regulation of immunity by butyrophilins. Annu. Rev. Immunol. 34, 151-172 (2016).

15. Chapoval, A. I. et al. BTNL8, a butyrophilin-like molecule that costimulates the primary immune response. Mol. Immunol. 56, 819-828 (2013).

16. Nguyen, T., Liu, X. K., Zhang, Y. \& Dong, C. BTNL2, a butyrophilin-like molecule that functions to inhibit T cell activation. J. Immunol. (Baltimore, Md.: 1950). 176, 7354-7360 (2006).

17. Arnett, H. A. et al. BTNL2, a butyrophilin/B7-like molecule, is a negative costimulatory molecule modulated in intestinal inflammation. J. Immunol. (Baltimore, Md.: 1950). 178, 1523-1533 (2007).

18. Yamazaki, T. et al. A butyrophilin family member critically inhibits T cell activation. J. Immunol. (Baltimore, Md.: 1950). 185, 5907-5914 (2010).

19. Ammann, J. U., Cooke, A. \& Trowsdale, J. Butyrophilin Btn2a2 inhibits TCR activation and phosphatidylinositol 3-kinase/Akt pathway signaling and induces Foxp3 expression in T lymphocytes. J. Immunol. (Baltimore, Md.: 1950). 190, 5030-5036 (2013).

20. Swanson, R. M. et al. Butyrophilin-like 2 modulates B7 costimulation to induce Foxp3 expression and regulatory T cell development in mature T cells. J. Immunol. (Baltimore, Md.: 1950). 190, 2027-2035 (2013).

21. Smith, I. A. et al. BTN1A1, the mammary gland butyrophilin, and BTN2A2 are both inhibitors of T cell activation. J. Immunol. (Baltimore, Md.: 1950). 184, 3514-3525 (2010).

22. Vantourout, P. et al. Heteromeric interactions regulate butyrophilin (BTN) and BTN-like molecules governing $\Gamma \delta$ T cell biology. Proc. Natl. Acad. Sci. U. S. A. 115, 1039-1044 (2018).

23. Compte, E., Pontarotti, P., Collette, Y., Lopez, M. \& Olive, D. Frontline: Characterization of BT3 molecules belonging to the B7 family expressed on immune cells. Eur. J. Immunol. 34, 2089-2099 (2004).

24. Yamashiro, H., Yoshizaki, S., Tadaki, T., Egawa, K. \& Seo, N. Stimulation of human butyrophilin 3 molecules results in negative regulation of cellular immunity. J. Leukoc. Biol. 88, 757-767 (2010).

25. Chen, L., Fakiola, M., Staines, K., Butter, C. \& Kaufman, J. Functional alleles of chicken BG genes, members of the butyrophilin gene family, in peripheral T cells. Front. Immunol. 9, 930 (2018).

26. Linsley, P. S., Peach, R., Gladstone, P. \& Bajorath, J. Extending the B7 (CD80) gene family. Protein Sci. Publ. Protein Soc. 3 , 1341-1343 (1994).

27. Yang, Y. et al. Characterization of B7S3 as a novel negative regulator of T cells. J. Immunol. (Baltimore, Md.: 1950) 178, 3661-3667 (2007).

28. Zhu, H. et al. Gene-based genome-wide association analysis in European and Asian populations identified novel genes for rheumatoid arthritis. PLoS One. 11, e167212 (2016).

29. Longhi, M. S., Mieli-Vergani, G. \& Vergani, D. Regulatory T cells in autoimmune hepatitis: An updated overview. J. Autoimmun. 119, 102619 (2021).

30. Su, M., Lin, Y., Cui, C., Tian, X. \& Lai, L. ERMAP is a B7 family-related molecule that negatively regulates T cell and macrophage responses. Cell Mol. Immunl. 18, 1920-1933 (2020).

31. Gavin, M. A. et al. Foxp3-dependent programme of regulatory T-cell differentiation. Nature 445, 771-775 (2007).

32. Bettelli, E. et al. Reciprocal developmental pathways for the generation of pathogenic effector TH17 and regulatory T cells. Nature 441, 235-238 (2006).

33. Lin, Y. et al. Skint8, a novel B7 family-related molecule, negatively regulates T cell responses. J. Immunol. (Baltimore, Md.: 1950) 203, 400-407 (2019).

34. Hua, D. et al. Soufeng Sanjie formula alleviates collagen-induced arthritis in mice by inhibiting Th17 cell differentiation. Chin. Med. UK 16, 39 (2021).

35. Woo, S. J. et al. Myeloid Sirtuin 6 deficiency accelerates experimental rheumatoid arthritis by enhancing macrophage activation and infiltration into synovium. EBioMedicine 38, 228-237 (2018).

36. Yu, Y. et al. Bixin attenuates experimental autoimmune encephalomyelitis by suppressing TXNIP/NLRP3 inflammasome activity and activating NRF2 signaling. Front. Immunol. 11, 593368 (2020).

\section{Acknowledgements}

This work was supported by grants from Science and Technology Support Program of Guizhou Province [Qiankehezhicheng (2020)4Y230, Qiankeherencaipingtai (2020) 4103 to MS], National Natural Science Foundation of China [NSFC 82060151 to MS], National Natural Science Foundation of China [NSFC 82160151to RH], Program for Science and Technology Excellent Talents in University of Guizhou Province [QianjiaoheKYzi (2017)071 to $\mathrm{RH}]$.

\section{Author contributions}

X.H., J.L., R.H., Y.H., J.G. and W.Y. participated in data collection and analysis. F.H., R.H., P.L. and M.S. participated in the design of the study. X.H., M.S. and L.L. participated in the writing of the manuscript and data interpretation. All authors read and approved the final manuscript.

\section{Competing interests}

The authors declare no competing interests.

\section{Additional information}

Supplementary Information The online version contains supplementary material available at https://doi.org/ 10.1038/s41598-021-98443-5.

Correspondence and requests for materials should be addressed to L.L. or M.S.

Reprints and permissions information is available at www.nature.com/reprints.

Publisher's note Springer Nature remains neutral with regard to jurisdictional claims in published maps and institutional affiliations. 
(c) (i) Open Access This article is licensed under a Creative Commons Attribution 4.0 International cc) License, which permits use, sharing, adaptation, distribution and reproduction in any medium or format, as long as you give appropriate credit to the original author(s) and the source, provide a link to the Creative Commons licence, and indicate if changes were made. The images or other third party material in this article are included in the article's Creative Commons licence, unless indicated otherwise in a credit line to the material. If material is not included in the article's Creative Commons licence and your intended use is not permitted by statutory regulation or exceeds the permitted use, you will need to obtain permission directly from the copyright holder. To view a copy of this licence, visit http://creativecommons.org/licenses/by/4.0/.

(C) The Author(s) 2021 